\title{
YEAST CELLS MAY USE AUC OR AAG AS INITIATION CODON FOR PROTEIN SYNTHESIS
}

\author{
by \\ OLE OLSEN
}

Department of Physiology, Carlsberg Laboratory, Gamle Carlsbergvej 10, DK-2500 Copenhagen Valby

Keywords: Recombinant DNA, translation initiation, secretion

\begin{abstract}
A yeast expression plasmid without an ATG codon for initiation of mouse $\alpha$-amylase protein synthesis directs the synthesis and secretion of active enzyme indistinguishable from both native mouse $\alpha$-amylase and amylase synthesized from plasmids with normal ATG initiation codons. The initiation of amylase synthesis directed by this plasmid is at either an AUC or an AAG codon. In either case the amino acid sequence of the hydrophobic core and peptidase cleaving region of the signal peptide are normal, and the protein translation remains in frame with the structural gene of the mouse $\alpha$-amylase.
\end{abstract}

\section{INTRODUCTION}

Initiation of protein synthesis in eukaryotes is catalysed by a relatively large number of specific eukaryotic initation factors (eIFs) bringing about the formation of the $80 \mathrm{~S}$ initiation complex composed of mRNA, an $80 \mathrm{~S}$ ribosome and met-tRNA $A_{i}$ (13). Eukaryotic met-tRNA $A_{i}$ differs from its prokaryotic counterpart by being associated with the $40 S$ pre-initation complex before binding to mRNA (13). This suggests that the cell has a requirement for met-tRNA during an $_{\mathrm{i}}$ early step of the initiation process leading to assembly of the $80 \mathrm{~S}$ complex. The ability of the $40 \mathrm{~S}$ complex to recognize an AUG initiation codon in proper context is probably dependent on codon-anticodon interaction. Among the important features (13), the cap structure ( $\mathrm{m}^{7} \mathrm{G} 5$ 'pppN) at the 5' end of eukaryotic mRNA is essential for efficient initiation which usually occurs at the first AUG triplet downstream from the cap structure. From a survey of published DNA sequences it was concluded that the opti- mal context for initiation was ${ }_{G}^{A} N N A U G_{G}^{A}$ where a purine in position -3 (three nucleotides upstream of the AUG initiator codon) is most highly conserved.

Until recently it was generally believed that eukaryotic ribosomes initiate exclusively at AUG codons although it had been shown by RAJBHANDARY and GHOSH (24) that yeast mettRNA $_{i}$ may function with either AUG or GUG as initiation codon in a cell-free translation system from E. coli. At present, a few examples of non-AUG codons for initiation of protein synthesis are known from eukaryotes. In yeast cells UUG- and AUA-codons may be used in initiation of protein synthesis (34) but it is emphasized that the start codon must appear in a proper context. BECERRA et al. (2) have shown that the methionyl-tRNA dependent initiation of adeno-associated virus (AAV) B protein starts from an ACG codon, and ANDERSON et al. (1) have shown that an ACG codon (replacing the AUG used in vivo to initiate the synthesis of

Abbreviations: ADHI (PR) = alcohol dehydrogenase I (promoter); bp = base pair(s). 
bacteriophage $\mathrm{T} 7$ gene 0,3 protein) may function as initiation codon in a wheat germ cell-free protein synthesizing system.

In the present study a yeast plasmid directing the synthesis and secretion of low amounts of mouse salivary $a$-amylase has been sequenced in the region flanking the promoter and the cDNA coding for the secreted protein. It was found that the $\alpha$-amylase coding region was without an ATG codon for initiation of translation. This example of a heterologous gene in yeast cells being expressed without an AUG initiation codon shows that yeast cells may use either AAG or AUC codons for translation initiation. The secretion level of $\alpha$-amylase directed from this plasmid is low compared to plasmids with an ATG start codon. However, the pre- $\alpha$-amylase synthesized from mRNA without an AUG codon is apparently processed and secreted in the same manner as $\alpha$-amylase initiated from an AUG codon.

\section{MATERIALS AND METHODS}

\subsection{Strains and media}

E. coli K-12 strain JM101 (17) was used to propagate $\mathrm{M} 13 \mathrm{mp}$ phage vectors as described by Messing (18). Otherwise the E. coli K-12 strain JM83 (17) was used as host in bacterial cloning experiments as described by VIEIRA and MEsSING (30). The Saccharomyces cerevisiae strain DBY746 (29) was grown in either YPD or SC media (22).

\subsection{Enzymes and chemicals}

Radioactive nucleotides were purchased from New England Nuclear. All enzymes as well as deoxy- ànd dideoxynucleotides were from Boehringer Mannheim.

\subsection{Plasmids and DNA purification}

The yeast expression plasmid, pMA56, was kindly provided by Dr. B.D. HALL, University of Washington, Seattle, USA. pMS15 was one of several plasmids constructed by inserting a mouse $\alpha$-amylase cDNA gene behind the $A D H I$ gene promoter of plasmid pMA56 (29).

Recombinant plasmids were recovered from yeast cells as follows. Total DNA was prepared as described by STRUHL et al. (28). After incubation with RNase A, the DNA samples were extracted twice with an equal volume of phenol and once with chloroform, precipitated from $70 \%$ ethanol, washed, and resuspended in 10 mM-Tris-HCl, 1 mM-EDTA (pH 7.5). This solution was used to transform competent E. coli JM83 cells.

E. coli plasmid DNA was prepared by the method of BiRnBoIM and DolY (3) which for large scale preparations was followed by caesium chloride equilibrium centrifugation. Purification of specific DNA fragments from low melting temperature agarose gels was carried out as described by MANIATIS et al. (16).

\subsection{Transformations}

Transformation of E. coli with plasmid DNA was performed as described by COHEN et al. (8). Yeast cells were transformed according to the method of ITO et al. (12) using lithium acetate to induce competence. Yeast transformants were selected on SC medium without tryptophan and cells secreting $\alpha$-amylase were detected on similar medium supplied with $1 \%$ starch (29).

\subsection{DNA sequence determination}

The nucleotide sequence of the $\alpha$-amylase cDNA gene (9) and its 5' flanking regions was determined by the dideoxynucleotide chain termination method of SANGER et al. $(25,26)$ except that the elongation reaction temperature was $55^{\circ} \mathrm{C}$.

\subsection{Activity staining of secreted $\alpha$-amylase}

Yeast cells grown in liquid medium were spun down. The supernatant was concentrated and dialysed in an Amicon ultrafiltration unit. Nondenaturing electrophoretic separation of the concentrated supernatant polypeptides was carried out in $13 \%$ polyacrylamide gels using a Tris-glycine buffer system, pH 8,3 (14).

Amylase activity was visualized by incubating the gels for 2 hours at $37^{\circ} \mathrm{C}$ in a $50 \mathrm{~mm}$-phosphate buffer (pH 6,9) containing 4\% starch and $0,08 \% \mathrm{NaCl}(4,27)$. After rinsing in water the 


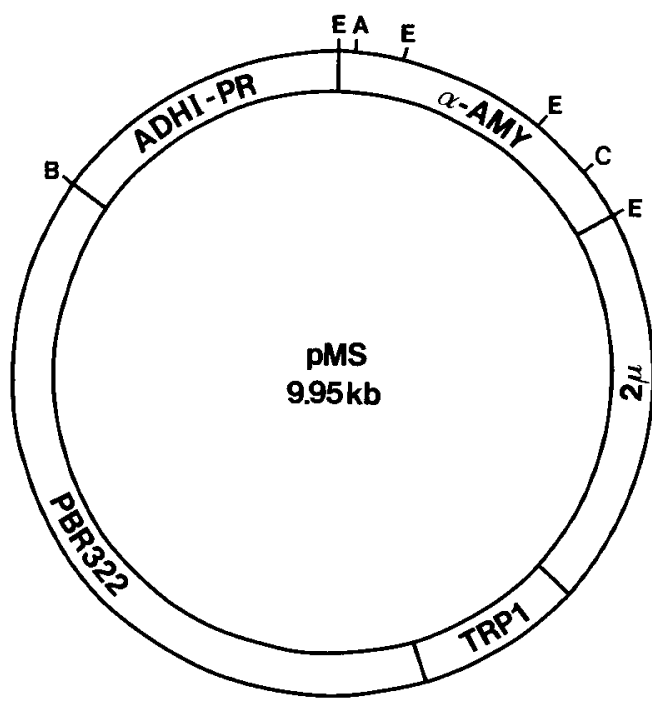

Figure 1. Physical map of $\alpha$-amylase expression plasmids. Mouse salivary $\alpha$-amylase cDNA is inserted adjacent to the yeast $A D H I$ gene promoter. The plasmid contains a yeast TRPI gene for selection and the origin of replication from the yeast $2 \mu$ circular plasmid. The plasmid also contains most of the E. coli plasmid pBR322 including both the ampicillin resistance gene and the origin of replication. Cleavage sites for restriction enzymes ApaI (A), BamHI (B), ClaI (C) and EcoRI (E) are shown.

gels were stained for 5-15 minutes in a $1 \% \mathrm{I}_{2}-\mathrm{KI}$ solution. Bands with amylase activity appeared as clear regions against a dark background.

\section{RESULTS AND DISCUSSION}

This report presents results of the analysis of an aberrant plasmid among a series of plasmids directing different levels of $\alpha$-amylase secretion from yeast (Figure 1). The plasmids were constructed by inserting Bal31 exonuclease treated $\alpha$-amylase cDNA in the yeast expression vector pMA56 using EcoRI linkers (29).

Among these plasmids one, pMS15, gave rise to low level of amylase secretion from yeast. It was chosen for further analysis and the nucleotide sequence flanking the $A D H I$ gene promoter and the $\alpha$-amylase cDNA was determined. In Figure 2 the nucleotide sequence is shown in comparison with the sequence of the analagous region from plasmid pMS12 which directs high level of amylase secretion from yeast cells. While plasmid pMS1 2 contains a complete $\alpha$-amylase coding region the nucleotide sequence found in pMS15 seems to represent an aberrant cloning event where the $\alpha$-amylase cDNA has been inserted in the vector via an EcoRI* site present in position +5 of the coding region, i.e. within the second codon.

The sequence specificity of EcoRI* activity is not quite clear, but the activity may be induced as a result of increased glycerol concentration in the reaction mixture (6). POLISKY et al. (23) observed EcoRI* activity under conditions of elevated $\mathrm{pH}$ and low ionic strength. They suggest that EcoRI* cleaves between the first and second base of the sequence NAATTN thereby generating the same type of 5' protruding ends as normal EcoRI digestion. During the construction of the pMS plasmid series a $\mathbf{3 0}$ fold molar excess of EcoRI linker was used; subsequently the linkers were digested with EcoRI using standard conditions. Yet it seems that a few EcoRI* sites were cleaved. The generated restriction fragments were cloned in the EcoRI site of the vector pMA56.

PMS12

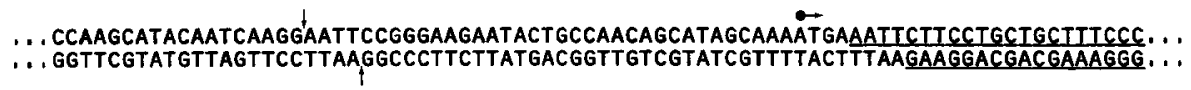

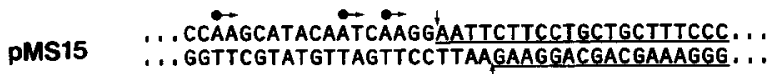

Figure 2. Comparison of the nucleotide sequence flanking the promoter and the $\alpha$-amylase cDNA of plasmids pMS12 and pMS15. Vertical arrrows indicate where the $\alpha$-amylase cDNA is inserted into the EcoRI site of the yeast expression plasmid pMA56. The common sequence between the $\alpha$-amylase sequence of pMS12 and pMS15 is underlined. The start codon ATG is marked in pMS12, while the putative start codons are marked in pMS15. 


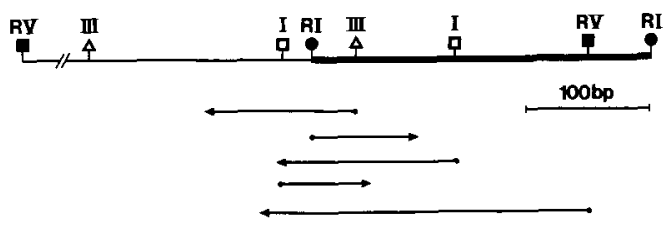

Figure 3. Sequencing strategy. Restriction map of the 3 ' region of the $A D H I$ gene promoter (thin line) and the 5 ' region of the $\alpha$-amylase cDNA (heavy line). Shown are the restriction sites for AluI(I), EcoRI(RI), EcoRV (RV) and HaelII (III). Horizontal arrows indicate regions where nucleotide sequence determination was obtained by dideoxynucleotide sequencing.

However, this aberrant cloning event might have happened during subcloning of the 5 , EcoRI fragment of the cDNA in preparation for sequencing, inferring that the yeast cells might contain an intact 5' EcoRI fragment. Therefore, non-EcoRI restriction fragments flanking the promoter and the cDNA were isolated from pMS15, subcloned in M13 and the nucleotide sequences determined (Figure 3 ). The results from this analysis showed that the sequence previously derived was not an artifact introduced during subcloning.

Further evidence for plasmid pMS15 directing synthesis of $\alpha$-amylase in spite of missing the ATG initiation codon was obtained by isolating the plasmid from yeast cells. The nucleotide sequence of the DNA fragment of interest was determined and it was found to be identical with the originally obtained sequence.

A functional in vivo control test was also performed. The BamHI-Clal fragment including the $A D H I$ gene promoter and most of the $\alpha$-amylase cDNA (Figure 1) in pMS15 was replaced by the analagous fragment from pMS12. The new recombinant plasmid pMS1215 directs an $\alpha$-amylase secretion level comparable to pMS12 (Figure 4). A plasmid constructed by the reciprocal exchange of fragments, pMS15-12, directs an $\alpha$-amylase secretion level comparable to pMS15 (Figure 4).

The $\alpha$-amylase from concentrated yeast culture supernatants was analysed in non-denaturing polyacrylamide gels (Figure 5). Zones of amylase activity were revealed by iodine staining after incubating the gel in a $4 \%$ starch solution. The gel system used for this analysis is very sensitive. It has been used to separate mouse pancreatic $\alpha$-amylase isoenzymes (10) which subsequently have been shown to differ only by one neutral amino acid (5). The amylase banding patterns from pMS 12 (a plasmid construction with normal ATG initiator codon) and pMS15 are indistinguishable from that of mouse salivary $\alpha$-amylase. The occurrence of multiple bands of $\alpha$-amylase activity may be due to glycosylated and unglycosylated forms of the $a$-amylase enzyme. These results indicate that plasmid pMS15 directs transcription of an mRNA encoding $\alpha$-amylase with a signal peptide which is cleaved off in the same position as in native mouse $\alpha$-amylase.

Two ATG triplets are located in the $A D H I$ gene promoter 189 and 251 bp upstream from the cDNA gene. Both these ATGs are in frame with a TAA stop codon and cannot be used for $\alpha$-amylase synthesis. In the normal $\alpha$-amylase cDNA the second ATG codon is located $288 \mathrm{bp}$ downstream from the initiation codon.

From a survey of available sequence data KOZAK (13) found that functional initiator

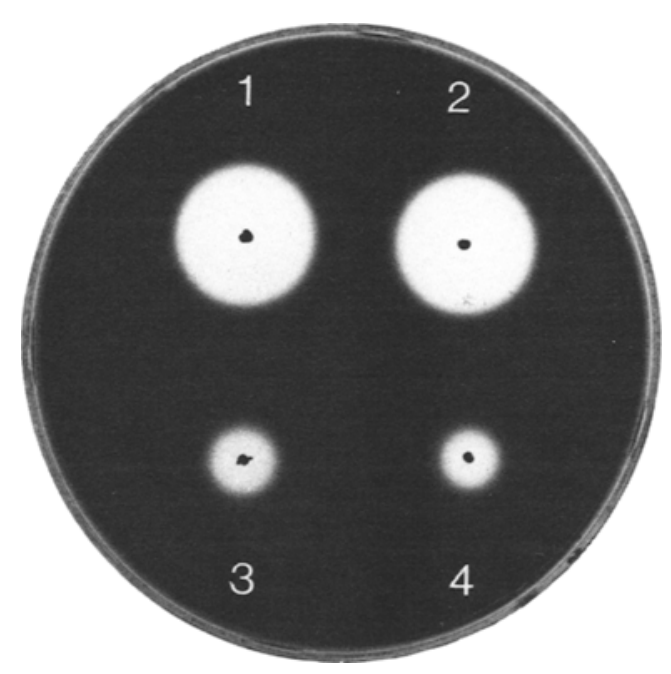

Figure 4. Secretion of $\alpha$-amylase from yeast. Yeast cells transformed with plasmid pMS12 (1), pMS12-15 (2), pMS15 (3) and pMS15-12 (4) were incubated over night on plates containing $0.1 \%$ starch. The plates were stained with iodine vapour. A halo shows that the cells secrete $\alpha$-amylase to the medium. 


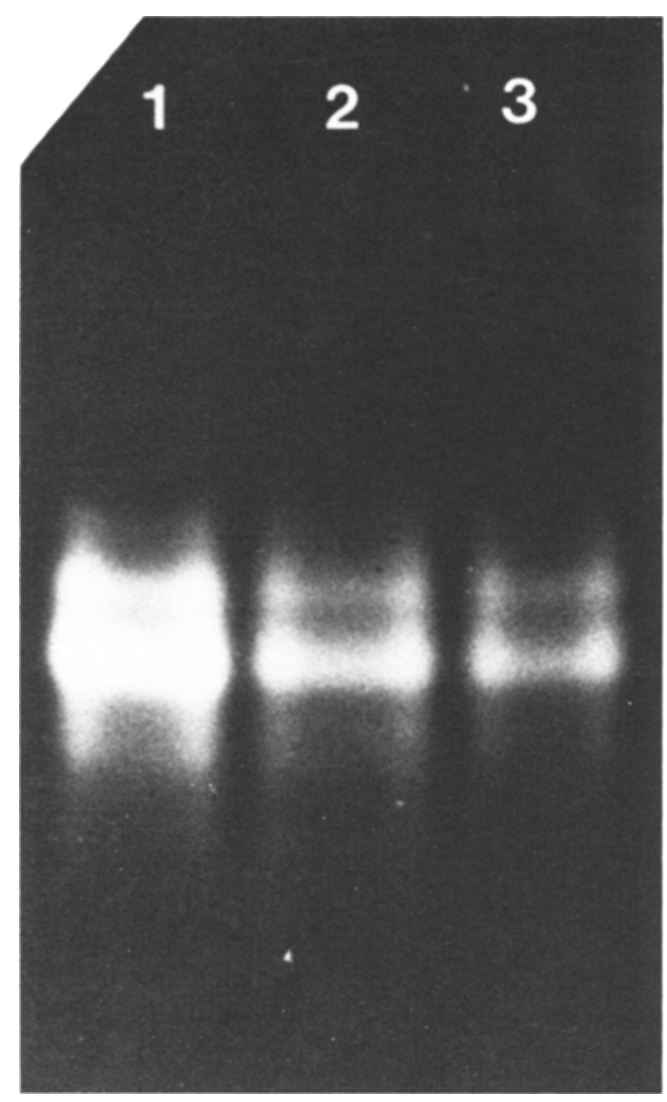

Figure 5. Activity staining of secretion products. Electrophoresis was carried out on a polyacrylamide gel which was stained for $\alpha$-amylase activity. Migration was from the top of the gel. Lane 1: native mouse salivary $\alpha$-amylase. Lane 2: $\alpha$-amylase (initiation codon ATG) secreted from yeast cells transformed with plasmid pMS12. Lane 3: $\alpha$-amylase secreted from yeast cells transformed with plasmid pMS15.

codons in eukaryotic cells occur in a restricted sequence context where ${ }_{G}^{A} \mathrm{NNAUG}_{G}^{A}$ is most frequently observed. Applying this observation on the potential initiation codons in frame with the coding sequence of $\alpha$-amylase (Figure 2 and Figure 6) it may be seen that all potential initiation sites have an $\mathrm{A}$ in position -4. The sequence pMS15-I with ATC as potential initiation codon resembles the normal sequence in pMS12 and the consensus most. It is not believed that other initiation codons than those shown in Figure 2 and Figure 6 are used because
${ }_{G}^{A} N N A \cup G A$

$\begin{array}{ll}\text { PMS12 } & \text { AAA } \\ \text { pMS15-L } & \text { ACC } \underline{A A G C} \\ \text { pMS15-I } & \text { ACA AUCA } \\ \text { pMS15-S } & \text { ATCA AAGG }\end{array}$

Figure 6. The most frequently used sequence context around AUG triplets in eukaryotic mRNAs (top line) is compared to the sequence around the initiator codon from pMS12 and the three possible initiation codons from pMS 15. Initiator codons are underlined.

peptide synthesis does not occur if a codon-anticodon recognition mismatches by two or three nucleotides (19).

A polypeptide initiated from one of the three proposed initiation codons shown in Figure 2 and Figure 6 can clearly be precursor of a secreted protein $(32,33)$ and indeed each of the amino acid sequences shown in Figure 7 has the essential characteristics of a signal peptide: A variable $\mathrm{N}$-terminal sequence followed by a core of hydrophobic amino acids preceeding the site at which the signal sequence region is cleaved off from the mature protein. The only difference among the putative signal peptides is the $\mathrm{N}$-terminal part, but this region is highly variable in secreted proteins $(32,33)$. All have the hydrophobic core as well as the region around the site for signal peptidase cleavage in common with normal pre- $\alpha$-amylase. An unfavourable aspect is the glutamic acid residue between the $\mathrm{N}$ and the core region of each putative signal peptide but that has been found in other eukaryotic signal peptides as well $(32,33)$. None of the three aligned signal peptides has a net negative charge, which, in E. coli, is known to be detrimental to translation $(11,31)$.

Misreading of genetic information is believed to take place at a low frequency either due to incorrect aminoacyl-tRNA selection or due to improper codon-anticodon recognition. Several suppressor tRNA genes are known $(7,15,20$, 21 ), and one cannot exclude that methionine is the $\mathrm{N}$ terminal amino acid in the signal peptide synthesized from pMS15. Thus, the main diffe- 


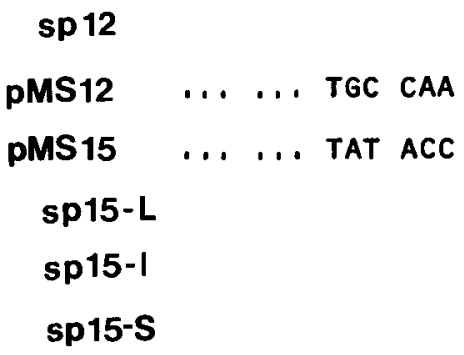

\begin{tabular}{|c|c|c|c|c|c|c|c|c|c|c|c|}
\hline & & & & Met & Lys & Phe & Phe & Leu & Leu & $\cdots$ & - \\
\hline $\mathbf{A G}$ & CAT & AGC & AAA & ATG & AAA & TTC & TTC & CTG & CTG & $\cdots$ & , \\
\hline $4 G$ & CAT & ACA & ATC & AAG & GAA & TTC & TTC & CTG & CTG & $\ldots$ & , \\
\hline et & $\mathrm{His}$ & Thr & Ile & Lys & Glu & Phe & Phe & Leu & Leu & $\cdots$ & $\cdots$ \\
\hline & & & $\begin{array}{l}\text { Met } \\
\text { I le }\end{array}$ & Lys & Glu & Phe & Phe & Leu & Leu & $\cdots$ & $\cdots$ \\
\hline & & & & $\begin{array}{l}\text { Met } \\
\text { Lys }\end{array}$ & Glu & he & Phe & Leu & I & $\ldots$ & . \\
\hline
\end{tabular}

Figure 7. Comparison of signal peptides possibly synthesized from pMS15 with the authentic $\alpha$-amylase signal peptide. The nucleotide sequences around the initiation codon of pMS12 and the putative initiation codons of pMS 15 are shown. The authentic signal peptide, sp12, is aligned with the putative signal peptides sp15-L, sp15-I and sp15-S. Suppressor mutations may result in a methionyl residue at the N-termini of the pMS15 signal peptides instead of either a lysine or an isoleucine residue.

rences between the signal peptides that may be synthesized from pMS15 and the authentic signal peptide, $\mathrm{sp} 12$, is the length of the amino terminal region and the glutamic acid residue already mentioned.

From the alignment of the signal peptides in Figure 7 it is not possible to predict which initiation codon is used by the translation apparatus, but translation of mRNAs (transcribed from a transcription plasmid) in a yeast homologous translation system followed by $\mathrm{N}$-terminal amino acid analysis of produced $\alpha$-amylase protein should make such a determination possible.

BECERRA et al. (2) speculate that use of nonAUG as initiation codon for translation of the AAV-B protein could regulate the relative synthesis of proteins $B$ and $C$ in vivo if these proteins are translated from the same mRNA. Assuming the initiation signal for AAV-B protein (initiation codon $A C G$ ) is weak compared to the signal for AAV-C protein (initiation codon AUG), then it would be possible for the cell to obtain a fixed ratio of $B$ protein/C protein.

Analagous control systems may operate in yeast cells. Perhaps the sequence context around one - or more - of the non-AUG initiation codons reported on here is homologous to sequences in the yeast genome where translation initiation events are regulated in a way comparable to synthesis of $A A V-B$ and $A A V-C$ proteins.

\section{ACKNOWLEDGEMENTS}

KARL KRISTIAN THOMSEN is acknowledged for scientific and practical guidance and encouragement throughout this work. KARINA BOSERUP is thanked for excellent technical assistance, and NINA RASMUSSEN for preparing the figures. JøRN TøNNES NIELSEN, University of Aarhus, is thanked for providing mouse salivary $\alpha$-amylase. DITER VON WETTSTEIN is thanked for support and encouragement and for critical reading of the manuscript. This work was supported by a grant No. 1984-133/001-84.127 from Teknologistyrelsen of The Ministry of Industry to DITER VON WETTSTEIN and M.C. KIELlandBRANDT.

\section{REFERENCES}

1. Anderson, C. W. \& E. Buzash-Pollert: Can ACG serve as initiation codon for protein synthesis in eucaryotic cells? Mol. Cell. Biol. 5, 3621-3624 (1985)

2. Becerra, S. P., J. A. Rose, M. Hardy, B. M. BAROUDY \& C. W. ANDERSON: Direct mapping of adeno-associated virus capsid proteins $B$ and $C: A$ possible ACG initiation codon. Proc. Natl. Acad. Sci. USA 82, 7919-7923 (1985)

3. BIRNBOIM, H. C.\& J. Doly: A rapid alkaline extraction procedure for screening recombinant plasmid DNA. Nucleic Acids Res. 7, 1513-1523 (1979)

4. BloOR, J. H. \& M. H. MEISLER: Additional evidence for close linkage of $A m y-I$ and $A m y-2$ in the mouse. J. Hered. 71, 449-451 (1980) 
5. Bodary, S., G. Grossi, O. Hagenbüchle \& P. K. WELLAUER: Members of the $A m y-2$ alpha-amylase gene family of mouse strain $\mathrm{CE} / \mathrm{J}$ contain duplicated 5' termini. J. Mol. Biol. 182, 1-10 (1985)

6. ChIRIKJIAN, J. G. \& J.GEORge; In: Gene Amplification and Analysis I, p. 74. Ed. J. G. Chirikjian, Elsevier North Holland, Inc., New York (1984)

7. Cigan, M.\& T.F. DonahuE: Translation initiation: mutational analysis of tRNA $\mathrm{i}_{\mathrm{i}}^{\text {Met }}$. Cold Spring Harbor Lab., Abstr. Pap. Meet. Mol. Biol. Yeast, p. 40 (1985)

8. Cohen, S. N.. A. C. Chang \& L. Hsu: Nonchromosome antibiotic resistance in bacteria. Genetic transformation of Escherichia coli by R-factor DNA. Proc. Natl. Acad. Sci. USA 69, $2110-2114$ (1972)

9. HagendüChle. O., R. Bovery \& R. A. Young: Tissue-specific expression of mouse $\alpha$-amylase genes: nucleotide sequence of isoenzyme mRNAs from pancreas and salivary gland. Cell 21, 179-187 (1980)

10. HJORT, J. P.. A. J. Lusis \& J. T. Nielsen: Multiple structural genes for mouse amylase. Biochem. Genet. 18, 281-301 (1980)

11. Inouye, S., X. Soberon, T. Franceschini, K. NAKamURA. K. ITAKURA \& M. INOUYE: Role of positive charge on the amino-terminal region of the signal peptide in protein secretion across the membrane. Proc. Natl. Acad. Sci. USA 79, 34383441 (1982)

12. Ito, H., Y. Fukuda, K. Murata \& A. Kimura: Transformation of intact yeast cells treated with alkali cations. J. Bacteriol. 153, 163-168 (1983)

13. KOZAK, M.: Comparison of initiation of protein synthesis in procaryotes, eucaryotes, and organelles. Microbiol. Rev. 47, 1-45 (1983)

14. LaEmml. U, K.: Cleavage of structural proteins during the assembly of the head of bacteriophage T4. Nature 227, 680-685 (1970)

15. Liebman, S. W. \& J. A. ALL-Robyn: A non-Mendelian factor, [eta ${ }^{+}$, causes lethality of yeast omnipotent-suppressor strain. Curr. Genet. 8, 567-583 (1984)

16. Maniatis, T., E. F. Fritsch \& J. Sambrook: In: Molecular Cloning: A laboratory manual. Cold Spring Harbor Laboratory, Cold Spring Harbor, New York, pp 1-540 (1982)

17. MesSiNG,J.: A multi-purpose cloning system based on the single-stranded DNA bacteriophage M13. Recombinant DNA Technical Bulletin, NIH publications No. 79-99, 2, No. 2, pp. 43-48 (1979)

18. Messing. J: New M13 vectors for cloning. Methods Enzymol. 101, 20-79 (1983)

19. Négre, D. A. J. Cozzone \& Y. Cenatieno: Accuracy of natural messenger translation: analysis of codon-anticodon recognition in a simplified cellfree system. Biochemistry 25, 6391-6397 (1986)

20. Normanty, J. -M. Masson, L. G. Kleina, J. AbeLSON \& J. H. Miller: Construction of two Escherichia coli amber suppressor genes: tRNA and tRNA ${ }_{\text {CUA }}^{\text {Cys }}$, Proc. Natl. Acad. Sci. USA 83, 6548-6552 (1986)

21. Pearson, D., I. Willis, H. Hottinger, J. Bell, A. KuMAR, U. LeUPold \& D. SÖll: Mutations preventing expression of sup $\underline{3}$ tRNA ${ }^{\text {ser }}$ nonsense suppressors of Schizosaccharomyces pombe. Mol. Cell. Biol. 5, 808-815 (1985)

22. Petersen, J. G. L., M. C. Kielland-Brandt, S. Holmberg \& T. NiLSSON-TILLGREN: Mutational analysis of isoleucine-valine biosynthesis in Saccharomyces cerivisiae. Mapping of $i l v 2$ and $i l v 5$. Carlsberg Res. Commun. 48, 21-34 (1983)

23. Polisky, B., P. Greene, D. E. Garfin, B. J. McCARTHY, H. M. GoOdMaN \& H. W. BoYER: Specificity of substrate recognition by the EcoRI restriction endonuclease. Proc. Natl. Acad. Sci. USA 72, 3310-3314 (1975)

24. RajBhandary, U. L. \& H. P. Ghosh: Studies on polynucleotides. J. Biol. Chem. 244, 1104-1113 (1969)

25. Rasmussen, S. K. H. E. Hopp \& A. Brandt: Nucleotide sequences of cDNA clones for B1 hordein polypeptides. Carlsberg Res. Commun. 48, 187199 (1983)

26. SANGer, F., S. Nicklen \& A. R. COUlSon: DNA sequencing with chain-terminating inhibitors. Proc. Natl. Acad. Sci. USA 74, 5463-5467 (1977)

27. SiCK, K.\& J. T. NIELSEN: Genetics of amylase isoenzymes in the mouse. Hereditas 51, 291-296 (1964)

28. STRUhl, K., D. T. StinchComb, S. SCherer \& R. W. DAvis: High-frequency transformation of yeast: Autonomous replication of hybrid DNA molecules. Proc. Natl. Acad. Sci. USA 76, 1035 1039 (1979)

29. ThOMSEN, K. K.: Mouse $\alpha$-amylase synthesized by Saccharomyces cerevisiae is released into the culture medium. Carlsberg Res. Commun. 48, 545$555(1983)$

30. VieIRA, J. \& J. Messing: The pUC plasmids, an M13mp7-derived system for insertion mutagenesis and sequencing with synthetic universal primers. Gene 19, 259-268 (1982)

31. Vlasuk, G. P., S. Inouye, H. Ito, K. Itakura \& M. INOUYE: Effects of the removal of basic amino acid residues from the signal peptide on secretion of lipoprotein in Eschericia coli. J. Biol. Chem. 258, 7141-7148 (1983)

32. von Heijne, G.: Patterns of amino acids near signal-sequence cleavage sites. Eur. J. Biochem. 133, 17.21 (1983) 
O. OLSEN: Non-AUG initiation of translation

33. vON HeIJNE, G.: How signal sequences maintain cleavage specificity. J. Mol. Biol. 173, 243-251 (1984)

34. Zitomer, R. S., D. A. WALTHALl, B.C. RYMOND\&C.

P. HOLLENBERG: Saccharomyces cerevisiae recognize non-AUG initiation codons. Mol. Cell. Biol. 4, 1194-1197 (1984)

Accepted by E. LuND 